\title{
Perspectivas de pesquisa com a metodologia de Eye tracking em leitura e cognição no Brasil
}

\section{Research perspectives using Eye tracking methodology in reading and cognition in Brazil}

\author{
Adriana Blanco Riess* \\ adrianariess@unisc.br \\ Universidade de Santa Cruz do Sul \\ Rosângela Gabriel** \\ rgabriel@unisc.br \\ Universidade de Santa Cruz do Sul
}

\begin{abstract}
RESUMO: Este artigo investiga os últimos quarenta anos de pesquisas em leitura e cognição que utilizam a tecnologia de Eye Tracking (rastreamento ocular). Faz-se uma retomada das metodologias de pesquisa na área de psicolinguística, desde aquelas que analisam dados comportamentais do leitor até as mais recentes que lidam com neuroimagens. Em especial, descreve-se o avanço da pesquisa com o Eye tracking, tanto em universidades do exterior, como nos laboratórios brasileiros. O que se observou é que nos últimos 10 anos o Brasil passou de dois laboratórios em universidades para sete laboratórios que desenvolvem pesquisa sob várias perspectivas cognitivas em programas de pós-graduação em linguística, a maioria deles avaliados como muito qualificados pela CAPES. Isso significa que essa é uma tecnologia promissora para a área de leitura, que cada vez mais se justifica como necessária.
\end{abstract}

PALAVRAS-CHAVE: Metodologia de pesquisa. Leitura e cognição. Eye tracking. Compreensão leitora.

ABSTRACT: This article investigates the last forty years of research in reading and cognition using the technology of Eye Tracking. Methodologies in the area of psycholinguistics are reviewed, firstly from those that analyze behavioral data followed by the most recent ones that deal with neuroimaging. In particular, we describe the progress of research with Eye tracking, both in universities abroad, and in Brazilian laboratories. What has been observed is that in the last 10 years Brazil has risen from two laboratories in universities to seven laboratories that develop research under various cognitive perspectives in graduate programs in linguistics, most of which are evaluated as highly qualified by CAPES. This means that this is a promising technology for the reading area, which is increasingly justified as necessary.

KEYWORDS: Research methods. Reading and cognition. Eye tracking. Reading comprehension.

\footnotetext{
" Doutora em Letras e Linguística pela PUC-RS. Bolsista Doc-Fix do Programa de Pós-graduação em Letras da Universidade de Santa Cruz do Sul (UNISC), Edital 04/2018.

Doutora em Letras e Linguística pela PUC-RS. Docente permanente do Programa de Pósgraduação em Letras e Bolsista Produtividade em Pesquisa do CNPq na Universidade de Santa Cruz do Sul (UNISC)
} 


\section{Introdução}

O presente artigo discute o uso da tecnologia Eye tracking (rastreamento ocular) na área de pesquisa em leitura e cognição. Trata-se de um tipo de equipamento que rastreia os movimentos oculares durante uma tarefa de leitura, como a busca de uma informação específica ou a compreensão leitora do texto. Esse tipo de metodologia está baseada na crença das ciências cognitivas que nem todos os processos envolvidos na leitura e compreensão leitora podem ser analisados pelo que se observa no comportamento do leitor pela sua fala ou escrita. Outrossim, essa é uma ferramenta capaz de capturar o que subjaz ao aparato sensorial do leitor, nesse caso a visão, e que não está sob seu controle consciente.

O objetivo geral deste artigo é descrever os avanços metodológicos da área de pesquisa em leitura na abordagem da cognição humana tendo em vista os estudos que se têm realizado com o uso de tecnologias, como o rastreamento ocular, dentre outras, que auxiliam no entendimento do funcionamento da leitura. Esses métodos fazem a interface entre áreas do conhecimento, a medicina, por exemplo, com a linguística, já que se articulam com outras metodologias, como a captura de neuroimagens feitas por equipamentos como fMRI (Functional magnetic resonance imaging) ou ERP (event-related potential), e são analisadas com a finalidade de mostrar o que o cérebro faz enquanto lê. Esse tipo de pesquisa é ainda recente no Brasil, em relação ao equipamento eye tracker especificamente, que é o método de maior interesse neste artigo, no qual se faz uma retomada histórica dos trabalhos realizados nos últimos 40 anos e se aponta para novas perspectivas de uso que ampliam o que se sabe até o momento.

É importante que se esclareça desde o início que a pesquisa em leitura é uma necessidade do país, pois não há desenvolvimento sem uma nação culturalmente instruída. Nesse sentido, é redundante justificar esta investigação pela sua óbvia importância: o que é novo aqui é lançar mão de tecnologias antes usadas apenas pelas ciências da saúde. Entende-se, assim, que a leitura não é apenas um fazer ou um produto cultural, ao longo dos tempos. Ela foi incorporada pela biologia humana, o que Deheane (2012) chama de neurônios da leitura, de modo que ela pode afetar tanto o processamento quanto a arquitetura cerebral. É essa interface entre percepção e cognição, com a possibilidade de investigar a entrada da informação pela capacidade visual e seu processamento, que faz investir no uso do Eye tracking 
como método de pesquisa na leitura. A gravação momento a momento do que o olho faz, seja pelas retomadas, seja pelas fixações em determinadas palavras, potencializa o pesquisador a chegar a resultados mais precisos e menos intuitivos.

Para fins de fundamentação teórica da pesquisa, os artigos de Rayner (1998), nos Estados Unidos, e de Klein e Bulla (2010), no Brasil, são utilizados como fonte de informação inicial, já que eles mesmos fazem uma retomada dos laboratórios instalados nas universidades que desenvolveram pesquisas nessa área. Contudo, com o avanço das neurociências na última década, o que se observou é que novos grupos de pesquisa se formaram e novas perspectivas metodológicas surgiram com projetos que dizem respeito a estudos interdisciplinares com as ciências da linguagem. O que se afirma aqui também é que o uso de métodos que capturam imagens não pode ser tratado como modismo ou como pesquisa cujas novas tecnologias dão o tônus do estudo. Nesse sentido, esse seria um trabalho no nível apenas descritivo dos laboratórios: o que se quer é compreender porque esses institutos ou laboratórios emergiram nesse período a ponto de não apenas desbravar uma área, mas de redirecionar a linha de raciocínio de muitos pesquisadores em leitura.

A partir das considerações feitas acima sobre a emergência de estudos cognitivos na leitura e métodos específicos advindos das neurociências, o artigo está dividido em três partes. Na primeira seção, retoma-se a discussão sobre as metodologias de pesquisa na leitura, desde os testes de leitura mais tradicionais até os ora apresentados. Já na segunda seção, os trabalhos mais recentes realizados com a tecnologia de Eye tracking são detalhados e faz-se uma retomada da evolução do conhecimento nos últimos 40 anos. Finalmente, a terceira seção trata exclusivamente das pesquisas brasileiras e como a área está organizada com vistas para novos saberes sobre a leitura e sua relação com o que há de mais humano em nós, que é, afinal, a cognição. Este artigo traz uma contribuição inovadora para a área no Brasil, pois além de discutir sobre a contínua necessidade de pesquisas em leitura, haja vista os baixos índices nos testes internacionais, descreve uma metodologia, tal como a tecnologia de Eye tracking, que tem demonstrado ser de ponta na precisão dos estudos, mas ainda pouco utilizada no país. 


\section{Metodologias de pesquisa em psicolinguística}

\subsection{Metodologias de pesquisa em leitura e cognição}

As metodologias de pesquisa na ampla área da psicolinguística e em leitura e cognição podem ser classificadas em, pelo menos, dois tipos: as comportamentais e as que buscam correlatos cerebrais. Tomitch (2008) explica que os dados comportamentais envolvem medidas do desempenho do leitor durante uma tarefa de leitura, enquanto os dados cerebrais são obtidos através de equipamentos que captam as informações neuropsicológicas, tais como ERP (Event related potentials) ou fMRI (Functional magnetic resonance imaging). As do primeiro tipo são bastante comuns nos estudos linguísticos, pois avaliam o comportamento do leitor durante a tarefa realizada. Assim, é comum na área de leitura que se faça uma interface com testes da psicologia, porque não se trata apenas de avaliar os conhecimentos adquiridos pelo texto, uma vez que, em certa medida, isso seria avaliar a compreensão leitora. Trata-se de analisar processos mentais que ocorrem na leitura, tal como o papel da memória, as implicações do processamento da linguagem ou mesmo a consciência linguística exigida durante a leitura online.

A técnica de protocolo verbal tem sido bastante utilizada na área da leitura, porque à medida que o participante lê o texto, ele explica o que é capaz de entender ou não. Tais dados interessam ao pesquisador, pois além de informar sobre a consciência linguística do participante, também informa sobre suas capacidades cognitivas, tanto as mais baixas/básicas, por exemplo, as associações grafemafonema na decodificação, bem como as mais altas, o que é capaz de lembrar ou mesmo sua habilidade inferencial. Testes com o procedimento de Cloze (preenchimento de lacunas) ou de múltipla escolha, do mesmo modo, são muito utilizados como fonte de coleta de dados na leitura. Nesse último tipo, por exemplo, o design das perguntas pode também revelar a confiabilidade do teste, já que cabe ao pesquisador dar consistência interna às alternativas.

Testes psicométricos bastante comuns aos psicólogos também são utilizados na área de leitura, tendo em vista que são capazes de medir etapas ou estágios de algum tipo de desenvolvimento cognitivo. Durante a alfabetização, o TCLPP (Teste de Competência de Leitura Silenciosa de Palavras) descrito por Capovilla e Capovilla (2004) se propõe a avaliar o estágio de desenvolvimento da leitura ao 
longo das etapas logográfica, alfabética e ortográfica das crianças em fase de escolarização. Trata-se de reconhecer palavras e pseudopalavras, sendo estas últimas sequências de caracteres que compõem um todo pronunciável, mas carente de significados.

Quanto às técnicas experimentais, Leitão (2008) explica os testes online e offline utilizados na psicolinguística. Os experimentos offline são baseados em respostas dadas pelos participantes depois de terem lido ou ouvido uma frase ou um texto, ou seja, no momento em que o processamento já foi finalizado. Por outro lado, os experimentos online medem as reações obtidas no momento em que a leitura/audição está em curso: os dados são obtidos simultaneamente ao processamento. $\mathrm{O}$ uso de um ou outro tipo de método indica os tipos de informação linguística que se quer capturar em tempo real; enquanto os experimentos offline capturam informações que já foram integradas entre todos os níveis linguísticos (fonológico, morfológico, lexical, sintático e semântico), os experimentos online dão informação a respeito de processos mentais que acontecem antes que a integração entre todos esses níveis linguísticos esteja completa. Nesse último caso, é possível ao pesquisador analisar como os níveis interagem levando em conta a ordem temporal em que atuam. Uma técnica desse tipo é o self-paced reading, ou "leitura automonitorada", em que a frase é segmentada e lida na tela do computador, e o participante aperta o botão ao terminar de ler. Nesse sentido, há um controle do participante sobre o tempo de leitura de cada segmento.

Em relação aos testes de proficiência em línguas estrangeiras, necessários para a internacionalização das universidades no mundo, o design da avaliação que diz respeito à compreensão leitora não deixa de fora as capacidades cognitivas do leitor. Esses testes classificam o candidato em níveis de proficiência, e normalmente utilizam as já mencionadas técnicas Cloze ou múltipla escolha em tarefas de leitura. Não obstante, é igualmente comum a inserção de frases em determinados parágrafos do texto a ser lido, ou a escolha de um melhor título para cada parágrafo. De fato, esse tipo de tarefa cognitiva exige que o leitor faça, por um lado, uma leitura local e, por outro lado, uma leitura global do texto. Essa oposição avalia, nesse sentido, tanto a leitura top down (ou seja, do global para o local) quanto à bottom up (ou seja, do local ao global) ${ }^{1}$, e isso significa que há uma exigência desses exames

\footnotetext{
${ }^{1}$ Os termos em inglês top-down e botton-up são usados na literatura especializada para designar estratégias de leitura que partem, na primeira expressão, dos conhecimentos prévios do leitor em
} 
de proficiência por um leitor estratégico. Consequentemente, o leitor não deve apenas conhecer a língua estrangeira; mais ainda, ele deve saber mobilizar os recursos de que dispõe para a compreensão em leitura.

O que se observa nos testes internacionais de proficiência em língua estrangeira, tal como Cambridge ou TOEFL na língua inglesa, DELE no espanhol, DELF em Francês, é que o objetivo final é certificar, no caso da leitura, bons leitores e não apenas conhecedores da língua. É por essa razão que um aprendiz da língua $X$ ou $Y$ pode não ter um vocabulário tão amplo, nem ter grande acurácia sintática, mas se for bom leitor, o que em inglês se denominou um good reader, poderá ser considerado proficiente na leitura dessa língua.

Os métodos aqui brevemente descritos ainda são bastante utilizados na área de leitura. No entanto, conforme já foi mencionado, outras técnicas, principalmente as advindas nas neurociências, como $\mathrm{FMRI}$ ou ERP, ainda incipientes no Brasil, mas com potencial de responder a novas perguntas, esboçam estudos cada vez mais interessantes. O Eyetracking, que é o foco do presente artigo, segue nessa direção; assim, dedica-se à próxima seção um olhar mais detalhado sobre o assunto.

\subsection{0 que é o Eye tracking}

A frase "Os olhos são a janela da alma", atribuída a Platão, pode servir de base para explicar como a investigação com o equipamento de Eye tracking faz sentido na pesquisa em leitura. Ainda que a frase ao inverso também seja verdadeira, ou seja, "a alma é a janela dos olhos", em ambos os casos há o pensamento de que os olhos carregam algum tipo de conhecimento. Abraham Lincoln (1858) conceitua leitura como a arte de comunicar pensamentos à mente, por meio dos olhos. Jackendoff (2001) afirma que $80 \%$ da entrada de informação nos seres humanos é pela visão; assim, há certa obviedade em pensar que um equipamento que rastreia os movimentos oculares durante a leitura seja eficiente para pesquisar a área.

O Eye tracker é uma tecnologia acoplada a um computador que grava o movimento dos olhos durante a realização de alguma tarefa cognitiva, dentre elas a

direção à materialidade do texto, daí a metáfora a que faz alusão a expressão "de cima para baixo", em oposição às estratégias que partem da materialidade do texto para níveis mais elevados, daí a expressão "debaixo para cima". Também já é consenso na literatura especializada que o leitor proficiente utiliza ambas as estratégias de forma complementar. 
leitura. Vários são os usos pelas diferentes áreas do conhecimento, por exemplo, para compreender o processamento sintático, como visto em Ventura, Maia e Guesser (2018). Também foi utilizado na tese de Klein (2012) com crianças com déficit de atenção, para citar exemplos de pesquisas no Brasil, ou ainda na área de marketing, para analisar focos de atenção nas imagens. Tais pesquisas têm o objetivo de investigar o tipo de movimento feito pelos olhos e sua relação com o texto lido.

São vários os movimentos oculares que dizem respeito ao comportamento do leitor, sendo as fixações e as sacadas os mais comuns nas pesquisas em leitura. As fixações se referem à atenção (medida em termos de tempo) que o olho do leitor despende em uma palavra. Se a fixação do olhar durou mais em uma determinada palavra ou sílaba do que em outras do texto, isso é um indício de que aquela palavra exigiu atenção especial. Isso poderia ocorrer pela falta de compreensão que ela gerou, ou porque ela é desconhecida, ou ao contrário, porque essa palavra possui qualidades/características que ajudam o leitor a melhor entender um contexto, ou ainda porque a palavra era pouco previsível naquele texto. Já as sacadas são os saltos que os olhos dão durante a leitura, pois os olhos estão sempre em movimento, mas nem sempre há linearidade. Há momentos em que digressões acontecem; isto é, o olho pode "pular" até uma palavra ou palavras lidas anteriormente: essas são as chamadas regressões; ou podem "pular" para frente, para atingir um objetivo, tal como prever um significado.

Durante um experimento realizado com o Eye tracking, o participante sentase diante do computador e o aparelho rastreador irá captar os movimentos dos olhos diante do estímulo que ele recebe, seja a leitura de textos ou imagens. Essas informações são gravadas por um software para serem analisadas posteriormente. Os programas mais atuais que gravam as informações na leitura online apresentamnas de modo variado, de tal forma que os dados podem ser mais facilmente manipulados. As representações mais comuns são os mapas de atenção e o scanpath: o primeiro mostra a região onde ocorreu o foco de atenção do leitor ao estímulo recebido, já o segundo faz o acompanhamento normalmente linear da leitura. Holmqvist et al. (2011) define o scanpath como a rota dos eventos oculomotores através do espaço dentro de um período de tempo. No entanto, há a possibilidade de detalhar muito mais os dados encontrados, porque softwares modernos podem calcular, por exemplo, a duração do evento (sacadas, micro 
sacadas etc.), o número de vezes em que o evento aconteceu, sua localização específica calculada ao longo da leitura, bem como especificações entre os olhos direito e esquerdo e o pico de velocidade, ou seja, a aceleração empregada na leitura.

Segundo Holmqvist et al. (2011), há inúmeras medidas dos movimentos oculares, e a amplitude de medidas depende da criatividade e do objetivo do pesquisador. As citadas neste artigo são as mais frequentes, mas medidas como piscadas, por exemplo, também são usadas para avaliar fadiga, sonolência ou sobrecarga do trabalho mental. A tecnologia de eye tracking, para esse autor, é melhor utilizada quando outros métodos servem como suporte de pesquisa. Isso aponta que uma combinação entre métodos de neuroimagens e outros comportamentais na área da psicolinguística podem garantir mais legitimidade ao estudo. No entanto, nem sempre é possível combinar metodologias em um único estudo, por isso a articulação dos achados é valiosa para a área de leitura e cognição, seja sobre os estudos relativos à acuidade visual e à atenção (RAYNER, 1998; RAYNER; POLLATSEK, 1992), memória (CARPENTER; JUST, 1976), ou mesmo à compreensão leitora (FRAZIER; RAYNER, 1982).

\section{Quarenta anos de pesquisas com o Eye tracking}

Há um importante artigo sobre o uso de Eye tracking publicado por Rayner (1998) que descrevia os primeiros 20 anos de pesquisa com essa tecnologia na relação da leitura com a cognição humana. Naquele período, o autor já mencionava que os avanços das pesquisas dependeriam da criatividade do pesquisador, já que muitas são as possibilidades de análise entre o que existe nos movimentos oculares com as capacidades cognitivas que são desempenhadas durante a leitura e o próprio texto. Em termos cognitivos, já se sabe que, à medida que o texto se torna conceitualmente mais difícil, a duração das fixações aumenta e o comprimento das sacadas diminui. Assim como as fixações aumentam, a frequência de regressões também aumenta (RAYNER; POLLATSEK, 1992). Em relação às questões dependentes da tipografia do texto, o estudo sobre os movimentos oculares também demonstrou ser eficiente, pois os pesquisadores descobriram que um texto considerado conceitualmente acessível, isto é, mais fácil de ser compreendido, sofre poucas interferências tipográficas, por exemplo. No entanto, essas interferências 
tipográficas, tal como qualidade da impressão, variações da fonte ou comprimento da linha influenciam nos movimentos oculares (RAYNER; INHOFF, 1981). Esses achados foram importantes para fins de publicação de livros didáticos mais adequados às capacidades visuais, para citar um exemplo.

Ainda, a pesquisa com Eye tracking nesses primeiros 20 anos descobriu que, durante os processos de compreensão, a fixação é de grande importância, já que a informação visual é adquirida em determinada região fixada. Verificou-se que, quando a fixação é mais longa do que a duração normal, deve haver problemas de compreensão, considerando que a duração normal de uma fixação é de 50-70ms. Além disso, observou-se também que as palavras de conteúdo são fixadas $85 \%$ das vezes e as palavras funcionais (artigos ou preposições, por exemplo) são fixadas $35 \%$ do tempo da leitura. Viu-se, ainda, uma estreita relação entre o tamanho das palavras e as fixações, bem como a compreensão e o tamanho das sacadas (RAYNER; DUFFY, 1988). Nesse sentido, seria possível calcular o tempo que um bom leitor levaria não apenas para ler um texto, mas também para compreendê-lo em um nível menos superficial.

Passados os anos iniciais da pesquisa com o Eye tracking, muitos autores foram conclusivos ao entender que os bons leitores são muito específicos em seus movimentos oculares e atentos à parte do texto em que têm maior dificuldade (FRAZIER; RAYNER, 1982). Do mesmo modo, percebeu-se que os maus leitores se envolvem muito mais em regressões e retornos do que já foi lido. Isso significa dizer que uma leitura "truncada", pouco fluente, isto é, em que há uma grande exigência dos movimentos oculares na busca pelo significado, acaba por prejudicar ainda mais o que está sendo considerado de difícil compreensão. Esse raciocínio leva a crer que há uma tênue linha divisória entre a variação dos movimentos e a falta de compreensão de um texto complexo e a própria falta de compreensão a partir da variação dos movimentos. Aparentemente, não está claro se são as restrições impostas pelo nosso aparato visual o causador de mais problemas de compreensão ou se problemas de ordem textual exigem mais daquilo que a fisiologia restringe.

De fato, é possível dizer que tanto as restrições fisiológicas que ocorrem durante a leitura quanto a complexidade linguística ou de conteúdo do texto estejam em jogo quando há falta de compreensão. É importante destacar isso aqui porque tal afirmação só foi possível de ser confirmada com as pesquisas que utilizaram Eye tracking e demonstraram esse impasse entre causa e efeito. Nesse sentido, há que 
se desconstruir, até certo ponto, o que torna um texto difícil de ser compreendido, porque não só a expressão linguística que ele contém é um fator a ser considerado, como tradicionalmente se tem pensado. O que se quer dizer é que não é simples desvincular o texto em si daquele que o lê, não somente em termos linguísticos e cognitivos, mas, em termos fisiológicos.

Com o passar dos anos, muitas pesquisas voltaram-se para a relação entre a complexidade do texto e a variação dos movimentos oculares, com ênfase nas questões de processamento gramatical. Já se sabe que certos fenômenos linguísticos são mais árduos para o leitor durante o processamento, como, por exemplo, anáforas, ambiguidade lexical ou certos tipos de sentenças, como algumas relativas. Just e Carpenter, já no ano de 1976, observaram que sentenças negativas levavam 56 ms a mais para serem processadas do que as afirmativas. Em pesquisa mais recente, Warren, McConnell e Rayner (2008) investigaram sentenças nas quais havia uma violação semântica entre verbo e argumento, tal como O homem usou uma foto para chantagear o espaguete ontem à noite. Nesse exemplo, os autores observaram que havia uma fixação mais longa em espaguete, em razão da condição semântica impossível ou implausível, e isso evitou a continuidade da leitura. Por questões de tamanho deste artigo, não é possível detalhar a pesquisa, mas a descoberta interessante dos autores é que a ruptura aconteceu por causa da semântica lexical e não por causa do conhecimento de mundo do leitor que, a princípio, contaria com o contexto para a compreensão. Isso desmistifica a ideia de que eventos implausíveis ou fantasiosos, como o do exemplo, não são aceitos por causa do conhecimento de mundo per se. Essa afirmação corrobora a conhecida frase utilizada por Chomsky "ideias verdes incolores dormem furiosamente", porque explica como o conhecimento sintático pode dar sentido a textos incongruentes, como ideias verdes e incolores, mas que podem ganhar significado no nível poético ou imaginário.

Além das pesquisas realizadas na área da leitura, o que se convencionou chamar em termos técnicos pelos psicolinguistas que usam Eye tracking o Paradigma da leitura, há pesquisas que se interessam por imagens em movimento ou imagens e sons. Esses estudos são chamados de Paradigma do mundo visual, porque tratam da captura dos movimentos dos olhos quando diante de imagens ou imagens e sons, e não pela leitura de letras. No estudo realizado pelos pesquisadores alemães Onat, Libertus e Konig (2007), mostrou-se que os olhos, 
diante de uma paisagem natural, tal como um deserto, em combinação com um som, como o de pássaros, conforme o estudo, fixam mais onde a lateralização do som acontece. Assim, há menos chances de a atenção dispersar quando há multimodalidade do estímulo, ou seja, quando som e imagem estão em conjunto. Essa pesquisa é de interesse para a área do cinema, por exemplo, quando o diretor tem o objetivo da atenção total em uma imagem, podendo, assim, a sonorização estimular a concentração. Para a área da tradução, pode-se pensar que a legendagem de filmes possa ser um estímulo capaz de desconcentrar o espectador/leitor, porque as imagens e sons acabam por concorrer com a leitura das palavras.

Por fim, o que se observa com o avanço da pesquisa em leitura com a tecnologia de Eye tracking é que ela permite uma gama de possibilidades que interessam à área da linguagem, desde o processamento da língua escrita no que tange às dificuldades gramaticais, às questões cognitivas, como os custos cognitivos que o leitor empenha durante uma tarefa de leitura. Essa tecnologia também permitiu que se investigassem novas formas de leitura, como, por exemplo, os textos multimodais que se tornaram frequentes, principalmente depois do fácil acesso à internet. Portanto, pesquisas que utilizem Eye tracking são contemporâneas o suficiente para auxiliar na busca por resposta às questões cognitivas que envolvem tanto o texto escrito, como as novas concepções textuais, tais como as que evocam nossos sentidos audiovisuais.

\section{Eye tracking no Brasil}

No Brasil, os estudos de linguagem que utilizam a metodologia de Eye tracking são relativamente recentes. Em Klein e Bulla (2010), as autoras afirmam que, na época da publicação do artigo, somente dois laboratórios de pesquisa em linguagem dispunham desse equipamento, o da UFRJ e o da Mackenzie-SP. Passada uma década, pode-se dizer que há um avanço considerável, haja vista o crescimento da área de neurociências, linguagem e cognição. Para citar um exemplo, recentemente, o $50^{\circ}$ Congresso internacional da Abralin (Associação Brasileira de Linguística), realizado na Universidade Federal de Alagoas, no ano de 2019, contou com pesquisadores que desenvolvem projetos com Eye tracking. Nessa oportunidade, esses pesquisadores puderam interagir com o grupo de 
trabalho, ligados à psicolinguística ou aos estudos de linguagem e cognição, tornando possível observar o caminho traçado por projetos dessa natureza.

A partir da pesquisa em bases de dados acadêmicas (Google Acadêmico e Plataforma Lattes) com a palavra de busca "eye tracking", foi possível enumerar, pelo menos, cerca de sete universidades. Os laboratórios da UFRJ e Mackenzie-SP continuam em funcionamento. O professor Eliseu Macedo, da Universidade Mackenzie, e sua equipe têm se dedicado aos distúrbios da linguagem e leitura. Nessa mesma linha, a professora Ângela Klein, autora do artigo supracitado (KLEIN; BULLA, 2010), também fundou seu próprio laboratório na UFTPR. Quanto às investigações de Klein, por exemplo, ela analisa crianças com déficit de atenção e tempo de fixação em relações correferenciais na leitura. Os resultados mostram que esses leitores levam mais tempo para processar tais relações em um texto.

Ainda em relação às relações correferênciais, a professora Elisângela Teixeira, líder do grupo de estudos com Eye tracking na área de Letras, da Universidade Federal do Ceará, publicou estudo a partir do tempo de leitura e número e tempo de fixações. No estudo de Teixeira, Soares e Leitão (2013), os participantes eram alunos de graduação expostos à leitura de frases cuja área de interesse eram as relações de correferência em hiperônimos e hipônimos. Os autores concluem que o custo de processamento correferencial nas condições dos hiperônimos é mais baixo do que em hipônimos.

Vieira, Teixeira e Chaves (2017) analisaram a leitura de surdos em vídeos legendados. Conforme explicam os autores, foi explorada a velocidade da apresentação das legendas e a segmentação linguística na quebra de linha. As legendas foram apresentadas bem e mal segmentadas (quando a segmentação se dava no interior de um sintagma). As conclusões indicam que legendas segmentadas pobremente levaram a muitas regressões e à demora na primeira fixação da legenda. Além disso, a perda da leitura em certas partes da legenda levou a maior custo de processamento.

A Universidade de Santa Cruz do Sul (UNISC) adquiriu um equipamento de Eye tracking no ano de 2017. Um dos projetos de pesquisa desenvolvido diz respeito à desambiguação lexical e leitura em L2 (RIESS; GABRIEL, 2019) junto ao laboratório de Pesquisa em Leitura do Programa de Pós-Graduação em Letras. Em artigo em preparação, as pesquisadoras analisam as fixações e sacadas em palavras ambíguas (previamente selecionadas) durante a leitura em língua inglesa 
como L2. Foram selecionados 26 participantes com nível intermediário de conhecimentos na língua inglesa. Os resultados sugerem que a desambiguação acontece automaticamente durante a leitura, já que poucas fixações foram observadas nas polissemias e homonímias analisadas. Contudo, quando o leitor necessita desambiguar, o tempo de fixação é maior e as sacadas regressivas ocorrem para integrar a palavra ao contexto. Tais resultados acarretam em maior custo de processamento, bem como no aumento do tempo de leitura, o que pode levar a dificuldades na compreensão leitora.

Quanto ao rastreamento ocular como uma inovação da pesquisa no país, Klein e Bulla (2010) concluem, em seu artigo sobre Eye tracking no Brasil, que os estudos naquele período restringiam-se às interfaces entre Linguística, Psicologia e Medicina. Em termos de Linguística per se, as pesquisas até hoje analisam o processamento da linguagem muito mais sob uma perspectiva sintática, ainda que as interfaces com os outros subsistemas como a semântica e pragmática possam acontecer. Em Ventura, Maia e Guesser (2018), o estudo é sobre o estatuto sintático da categoria vazia na topicalização à esquerda; já em Maia, França e Machado (2018), o foco de análise é a ambiguidade de pronomes correferentes.

Por outro viés, Klein (2013) estuda pronomes correferentes. No entanto, os participantes da pesquisa são crianças diagnosticadas com TDAH, as quais usavam medicamentos prescritos para o distúrbio. Nos estudos mencionados sobre correferenciação, os resultados indicam maior custo cognitivo quando o leitor se depara com tal caraterística sintática, seja pelas fixações mais longas ou pela necessidade de regressões.

Por razões de limitação de espaço do artigo, não é possível realizar análise detalhada de mais estudos, mas sabe-se que as Universidades Federais de Minas Gerais e de Santa Catarina possuem pesquisadores que utilizam Eye tracking. Vale a menção a essas universidades, pois isso também sinaliza que a metodologia está em ascensão, e os resultados possivelmente contribuirão para novos conhecimentos sobre a leitura e sobre os processos cognitivos.

Ainda que o número de laboratórios tenha aumentado, pode-se dizer que, no Brasil, ainda há um campo de pesquisas a ser desbravado com a utilização de Eye tracking. Essa tecnologia permite que se avance muito mais, principalmente em relação às questões cognitivas que ocorrem durante a leitura. Essas questões dizem respeito ao trabalho da memória, à distribuição da atenção, ao papel do contexto, 
apenas para citar alguns. Isto ocorre porque os movimentos oculares, como as fixações, as regressões ou mesmo as piscadas, são indícios de que, na leitura, o jogo cognitivo vai além das palavras.

\section{Considerações finais}

A decisão de investigar perspectivas de pesquisa com a metodologia de Eye tracking na área de leitura e cognição decorre do avanço das pesquisas em ciências cognitivas que utilizam esta metodologia. São muitos os métodos para analisar dados sobre leitura e os processos cognitivos que estão envolvidos na complexidade de ler. O rastreamento ocular, Eye tracking, é um desses métodos, bastante produtivo para analisar informações que podem escapar da intuição do pesquisador. Esta é a principal justificativa para que o investimento em uma tecnologia dessa natureza seja válida para os estudos em leitura.

Conforme se afirmou neste artigo, há muito mais do que o reconhecimento de palavras na leitura; há mais em jogo também, mesmo das habilidades mais altas, como as inferências. A leitura exige nossa atenção, demanda esforço, inclusive fisiológico, requer a mobilização de conhecimentos alheios, muitas vezes, ao nosso controle consciente. Tendo tudo isso em mente é que se entende que a tecnologia de Eye tracking pode ser bastante produtiva para que se saiba mais sobre o assunto.

O artigo foi dividido em três seções. A primeira discutiu os métodos de pesquisa em leitura e cognição, não só os comportamentais, bem como aqueles que utilizam neuroimagens. É preciso reconhecer que a escolha por um método ou outro acontece em razão do objetivo da investigação, de sua natureza, e não por estar "em voga". De fato, o que se chamaria de "modismo" não pode ser confundido com o zeitgeist, isto é, o espírito da época, que parece delinear a epistemologia científica em determinados períodos da história da humanidade.

A segunda e terceira seções do artigo descreveram a linha de tempo dos estudos em Eye tracking, tanto em nível internacional quanto nacional. Percebeu-se que o país avançou nas investigações e que há um crescimento de laboratórios em outras universidades fora do eixo Rio - São Paulo, locais onde os primeiros laboratórios surgiram. Isso significa que o Brasil é capaz de fazer pesquisa de ponta nessa área; no entanto, não se pode assumir que esse método esteja disseminado 
porque o número de laboratórios com publicação ainda é pequeno quando comparado ao potencial da área.

Por fim, vale ressaltar que este artigo teve, por um lado, o objetivo de fazer uma retomada das pesquisas com o Eye tracking, principalmente no país, haja vista que passados dez anos das primeiras publicações já se vêem avanços. Por outro lado, o artigo buscou direcionar o leitor para as perspectivas das pesquisas com o rastreamento ocular. A palavra "perspectivas", presente no título, já aponta para o que se afirma: o Eye tracking lança luz, sob novos olhares, para o jogo cognitivo da leitura, pois não se investiga somente a língua e seu processamento, mas também a possibilidade de análise de déficits que impactam diretamente na leitura, como o da atenção e hiperatividade, bem como a própria dislexia. Ainda, questões da leitura em segunda língua também podem ser analisadas por essa perspectiva. Rayner (1998) retomou 20 anos de pesquisa em Eye tracking, portanto de 1978-1998. Passados mais 20 anos, os estudos com rastreamento ocular tomam forma no Brasil.

\section{Referências}

CAPOVILLA, Alessandra Gotuso; CAPOVILLA, Fernando Cézar. Alfabetização: método fônico. São Paulo: Memnon, 2004.

DEHAENE, Stanislas. Os neurônios da leitura. Porto Alegre: Penso. 2012.

DUFFY, Susan; RAYNER, Keith. Lexical ambiguity and fixation times in reading. Journal of memory and language, v1, n. 27, p. 429-46, 1988.

FRAZIER, Lyn; RAYNER, Keith. Making and correcting errors during sentence comprehension: Eye movements in the analysis of structurally ambiguous sentences. Cognitive Psychology, v.14, n. 1, p.78-210, 1982.

HOLMQVIST, Kenneth; NYSTRÖM, M.; ANDERSSON, R.; DEWHURST, R., JARODZKA, H.; VAN DE WEIJER, J. Eye tracking: A comprehensive guide to methods and measures. Oxford: Oxford University Press, 2011.

JACKENDOFF, Ray. Foundations of language: Brain, meaning, grammar, evolution. Oxford: Oxford University Press, 2001.

JUST, Marcel Adam; CARPENTER. A. Patricia. Eye fixations and cognitive processes. Cognitive psychology, v.8, no. 4, p.441-480,1976.

KLEIN, Ângela. O processamento da anáfora pronominal em crianças com Transtorno de Déficit de Atenção e Hiperatividade e em crianças disléxicas: um estudo através da análise dos movimentos oculares. 2013. Tese (Doutorado em Letras) - Faculdade de Letras,Pontifícia Universidade Católica do Rio Grande do Sul, 
Porto Alegre, 2013. Disponível em: http://tede2.pucrs.br/tede2/handle/tede/2097. Acesso em: 10 dez. 2019.

KLEIN, Ângela; BULLA, Julieane P. Eye-Tracking e linguística: aplicações e interfaces. Letrônica, vol.3, n.2, p. 235-249, 2010. Disponível em: http://revistas eletronicas.pucrs.br/ojs/index.php/letronica/article/view/7606. Acesso em: $10 \mathrm{dez}$. 2019.

LEITÃO, Márcio. Psicolinguística experimental: focalizando o processamento da linguagem. In: MARTELOTTA, Mário Eduardo (org.). Manual de Lingüística. São Paulo: Contexto, 2008. p.217-34.

MACHADO, Ana Luíza; FRANÇA, Aniela Improta; MAIA, Marcus. Resolução da ambiguidade no âmbito da correferência pronominal: um estudo psicolinguístico sobre a influência do contexto. ReVEL, vol. 16, n. 30, p. 108-125, 2018. Disponível em: http://www.revel.inf.br/pt/edicoes/?id=49. Acesso em: 10 dez. 2019.

ONAT, Selin; LIBERTUS, Klaus; KÖNIG, Peter. Integrating audiovisual information for the control of overt attention. Journal of Vision, v.7, n. 10, p. 1-16, 2007. Disponível em: https://jov.arvojournals.org/article.aspx?articleid=2192902. Acesso em: 10 dez. 2019.

RAYNER, Keith. Eye movements in reading and information processing: 20 years of research. Psychological bulletin. v. 124, n. 3, p. 372-422, 1998.

RAYNER, Keith; INHOFF, A. W. Morrison. Masking of foveal and parafoveal vision during eye fixations in reading. Journal of Experimental Psychology: Human perception and performance, v.7, n.1, p.167-179, 1981.

RAYNER, Keith; POLLATSEK, Alexander. Eye movements and scene perception. Canadian Journal of Psychology / Revue canadienne de psychologie, v.46, n.3, p. 342-376, 1992.

TEIXEIRA, Elisângela Nogueira; SOARES, Maria Elias; LEITÃO, Márcio Martins. Processamento da correferência interfrasal em relações de hierarquia semântica e proeminência sintática. In: Encontro Nacional da Associação Portuguesa de Linguística. Coimbra. Anais... Coimbra: Universidade do Algarve, 2013. p. 615-635.

RIESS, Adriana Blanco; GABRIEL, Rosângela. A desambiguação lexical durante a compreensão leitora em inglês como língua estrangeira. Letras de Hoje, 54, n.2, p. 181-190, 2019. Disponível em: http://revistaseletronicas.pucrs.br/ojs/index.php/fale/ article/view/32529. Acesso em: 10 dez. 2019.

TOMITCH Leda Maria. Aspectos cognitivos e instrucionais da leitura. Florianópolis: Ed. EDUSC. 2008.

VENTURA, Lorrane da Silva Neves Medeiros; MAIA, Marcus Antônio Rezende; GUESSER, Simone Lúcia. Estudo de rastreamento ocular sobre o estatuto sintático da categoria vazia na topicalização à esquerda sem retomada explícita no PB. 
ReVEL, vol. 16, n. 30, p. 108-126, 2018. Disponível em: http://www.revel.inf.br/ pt/edicoes/?id=49. Acesso em: 10 dez. 2019.

VIEIRA, Patrícia Araújo; TEIXEIRA, Elisângela Nogueira; CHAVES, Élida Gama. Caminhos do olhar: A movimentação ocular de espectadores surdos durante a exibição de vídeos legendados. Trab. linguist. apl., v. 56, n. 2, p. 493-526, 2017. Disponível em: http://www.scielo.br/scielo.php?script=sci_arttext\&pid=S0103$18132017000200009 \&$ Ing=en\&nrm=iso\&tlng=pt. Acesso em: 10 dez. 2019.

WARREN, Tessa; McCONNELL,Kerry; RAYNER, Keith. Effects of context on eye movements when reading about possible and impossible events. Journal of Experimental Psychology: Learning, Memory, and Cognition, v.34, n.4, p.1001-1010, 2008. Disponível em: https://www.ncbi.nlm.nih.gov/pmc/articles/PMC2667829/. Acesso em: 10 dez. 2019.

\section{AGRADECIMENTOS}

A redação deste texto contou com o apoio do Edital FAPERGS/CAPES 04/2018 DOCFIX (Processo 18/2552-0000536-3). Adriana Blanco Riess é bolsista DOCFIX na Universidade de Santa Cruz do Sul (RS, Brasil), onde atua em cooperação com a professora Rosângela Gabriel, docente permanente do Programa de Pós-graduação em Letras e Bolsista Produtividade em Pesquisa do CNPq. 